\title{
Contemplating the abyss
}

The role of environmental degradation in the collapse of human societies.

\author{
Collapse: How Societies Choose \\ to Fail or Succeed \\ by Jared Diamond \\ Viking/Allen Lane: 2005. 592 pp. \$29.95/£20

\section{William Rees}

Jared Diamond is a necessary antidote to Bjørn Lomborg (of The Skeptical Environmentalist fame) and other latter-day acolytes of Julian Simon who preach that environmental problems are largely bogus and that the human future is secure. Consider the facts: industrial humans are the most voracious predators in the world's oceans and, simultaneously, the most successful terrestrial carnivore ever to have walked the Earth. As if to underscore the merits of our generalist evolutionary strategy, we are also the dominant herbivore in grasslands and forests all over the planet (especially if we consider the demands of our 'industrial metabolism'). In short, humans are the most ecologically significant macro-consumers in every major ecosystem type on Earth (with the notable exception of deep marine vent communities, which we have only just begun to explore), and we are literally consuming ecosystems from within. Meanwhile, Earth scientists say that human activity is the most powerful geological force altering the face of the planet, and the erosive pace is accelerating.

Nothing bogus here - this is an ecological reality. Human behaviour towards the ecosphere has become dysfunctional and now arguably threatens our own long-term security. The real problem is that the modern world remains in the sway of a dangerously illusory cultural myth. Like Lomborg, most governments and international agencies seem to believe that the human enterprise is somehow 'decoupling' from the environment, and so is poised for unlimited expansion. Jared Diamond's new book, Collapse, confronts this contradiction head-on. It is essential reading for anyone who is unafraid to be disillusioned if it means they can walk into the future with their eyes open.

As suggested by its title, this book is about societal collapses - past, present and future — and the factors that cause human societies to fail. But it is also a history of success, of societies that were able to confront their problems and thrive, sometimes for millennia. Diamond reasons that, for all the trappings of modernity, the human past presages the human future, and thus provides "a rich database from which we can learn". His primary mission is to determine the ecological, political and cultural conditions that lead

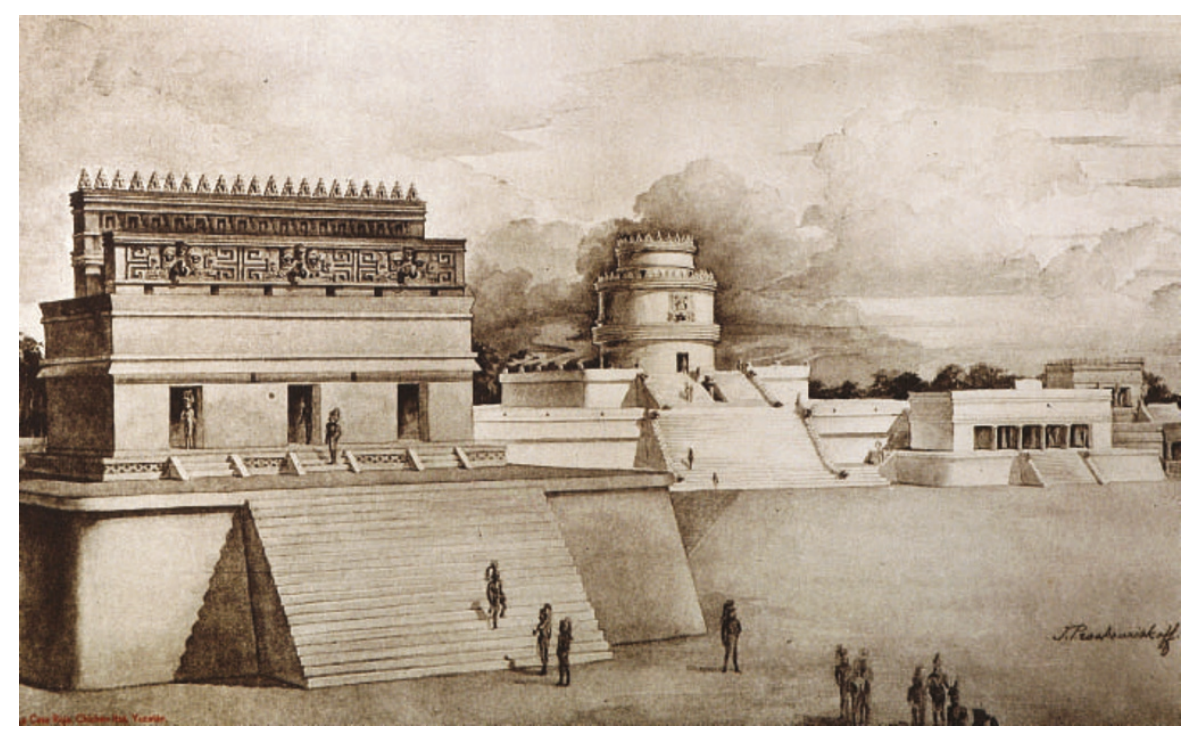

Before the fall: Chichén Itzá was a thriving city until the collapse of the Mayan civilization.

to collapse and to contrast these with the conditions that favour success.

Diamond defines collapse as "a drastic decrease in human population size and/or political/economic/social complexity, over a considerable area for an extended time". He founds his analysis on systematic consideration of five sets of causal mechanisms. Any of the first four sets - damage that people inflict on their ecosystems, climate change, the actions of hostile neighbours, and loss of contact with trading partners (friendly neighbours) - may or may not be relevant to any particular case. The fifth set, however - how a society responds to the other classes of problems as they arise - is always a determinant of that society's future.

Collapse is based on a series of detailed case studies. Diamond begins with an affectionate portrait of modern-day Montana, revealing many of the socio-political and environmental uncertainties that cloud the state's future. The main purpose here is actually to establish common themes for subsequent chapters on societies that have long since completed the cycle to collapse: cultures on Easter Island, Pitcairn Island and Henderson Island in the South Pacific; the native American culture of the Anasazi; the Maya; and the Norse Greenland culture. These tragic failures are followed by several uplifting cases of societal success, including Tikopia in the South Pacific, the New Guinea highlands, and Japan during the Tokugawa era.

Diamond then provides a fuller exploration of the many rich parallels between these historic cases and select modern societies. The latter include the contemporary malthusian disasters of Rwanda and Haiti; the success (by developing-world standards) of the Dominican Republic; an emerging developing-world giant, China, which is the scariest case because of the staggering scale of its problems and potential global impacts; and Australia, a developed-world society reeling from ecological degradation but beginning to respond creatively. (Tellingly, however, Diamond's most realistic scenario for Australia sees it falling into decline under the weight of accelerating environmental problems, perhaps just ahead of the rest of the developed world.) Curiously missing from this section is a detailed consideration of the United States, Diamond's own country and the one imposing the greatest ecological load on the planet.

What emerges most clearly from Diamond's analysis is the central role played by environmental decay in undermining human societies. Eight ecological processes familiar to environmentalists today also plagued earlier societies: habitat destruction (such as deforestation and desertification), soil degradation (erosion, water-logging and salination), water supply problems, over-hunting, over-fishing, the impacts of introduced species, population growth pressures, and rising per capita impacts. The relative significance of each of these processes varies greatly from case to case, but all the ancient societies examined put themselves at risk, sometimes fatally so, by inadvertently undermining the very ecosystems that supported them - and modern societies have even more ecological spectres to banish.

Highlighting environmental degradation as a fundamental factor in societal collapse distinguishes Diamond's interpretation from 
that of Joseph Tainter in his 1988 book The Collapse of Complex Societies, which has long been the best-known book on the subject. Tainter developed a convincing argument that societies actually advance or 'complexify' as they respond creatively to major challenges. He therefore found it difficult to accept that any complex society with predeveloped administrative, organizational and technical coping skills would allow itself to succumb to emergent ecological problems. Instead, he placed the blame for collapse on socio-political instability resulting from diminishing returns to investment in problem solving - that is, on excessive complexity. Diamond concedes that the implosion of a vulnerable society might be triggered by an overstretched economy, dissolute leadership or enemy invasion, say, but argues that the ultimate cause is usually fragility caused by ecological degradation.

In the book's final section, Diamond focuses on practicallessons. Why do societies sometimes make such disastrous decisions? What can we 'moderns' usefully learn from the responses of ancient societies to environmental crises? What is the appropriate role of the private sector, transnational corporations in particular? Which of today's environmental trends are the most threatening and how do they differ from those that sank previous societies? Anticipating resistance to his findings from perennial optimists, Diamond includes well reasoned ripostes to a dozen common 'one-liner' objections to the seriousness of environmental problems and to the relevance of previous collapses to techno-industrial society.

In the end, Diamond's painstaking toil in the deep mines of history rewards him with sufficient nuggets of hope that he emerges "cautiously optimistic" about the human prospect. Modern society's ecological and geopolitical problems may be daunting but, in theory, they can be solved if we take the right decisions to reduce our ecological footprints. And let's not forget that we are uniquely positioned to learn from the collapse of previous societies.

Regrettably, theory and example do not always translate into practice. The most important lesson to be drawn from Collapse is that resilient societies are nimble ones, capable of long-term planning and of abandoning deeply entrenched but ultimately destructive core values and beliefs. This, in turn, requires a well informed public, inspired leadership and the political will to take decisions that go against the established order of things. In this light, the astute observer of contemporary geopolitics and ecological decline might be excused a descent into quiet despair.

William Rees is professor of ecological planning in the School of Community and Regional Planning, University of British Columbia, 6333 Memorial Road, Vancouver V6T 1Z2, Canada.

\section{A natural pioneer}

John James Audubon: The Making of an American

by Richard Rhodes

Knopf: 2004.528 pp. $\$ 30$

\section{John Fitzpatrick}

Some of the best-known icons of America's pioneer age endure through bloated mythologies of heroism generated by salesmanship and an American culture perpetually in demand of larger-than-life heroes. Not so John James Audubon, the most famous naturalist-artist in history. His monumental double-elephant folio production Birds of America holds a deserved place among the greatest artistic achievements of any era, and his writings provide our richest chronicle of North American natural history before the industrial revolution.

The mythology surrounding Audubon's life and character bestows on him a mixed review: mysterious birth and early childhood, commercial failure and debtors' prison, and long absences from his family. Audubon the legend has been painted as a bumbling businessman, a self-promoting dandy and a gallivanting nature-boy who abandoned wife and children for long periods to live in the woods and sketch birds. Audubon's serendipitous good fortune in marrying a patient and hard-working wife, Lucy Bakewell, and later becoming a partner with virtuoso engravers the Robert Havells, senior and junior, carry as much weight in fable as do his keen observational skills, passionate creativity, breakthrough artistic genius and scientific contributions.

In this masterful biography, the historian and novelist Richard Rhodes systematically debunks these persistent canards. This is a lively, interpretative tour through the personality, travels, business ventures, accomplishments and foibles of an extraordinary man. Beginning with Audubon's illegitimate birth in Saint-Domingue (now Haiti) in 1785 , Rhodes weaves together each turn of Audubon's difficult but colourful 61-year life with insightful commentary and vignettes that illustrate what life was like in the forested frontier west of the Appalachians. He underscores the turbulent social and economic forces at work in both Europe and America during the early nineteenth century.

Supported by generous quotes from his copious journals and correspondence, the Audubon we see here was a multi-talented, complex, hard-working and genuinely heroic family man. Handsome and lively - "his eyes alone commanded attention" - he had unrivalled physical dexterity and energy, loved to sing and dance, played the violin and flute, and excelled at fencing, marksmanship, horsemanship and - of course - art. Everyone he met remembered him vividly, and Rhodes' intimate portrait leaves little doubt that the reader would love to have known this man personally.

Rhodes casts Audubon's most famous business failures as earnest and promising ventures that collapsed at precisely the same moments, and for the same reasons, as virtually every other similar business in the country. After a shipping partnership in New Orleans was destroyed by embargoes caused by the war of 1812, Audubon successfully built up a new one along the rapidly developing Ohio River. Then, during America's first major economic depression (the panic of 1819), nearly every mercantile business in the country collapsed. Returning home after failing to collect a debt in New Orleans,

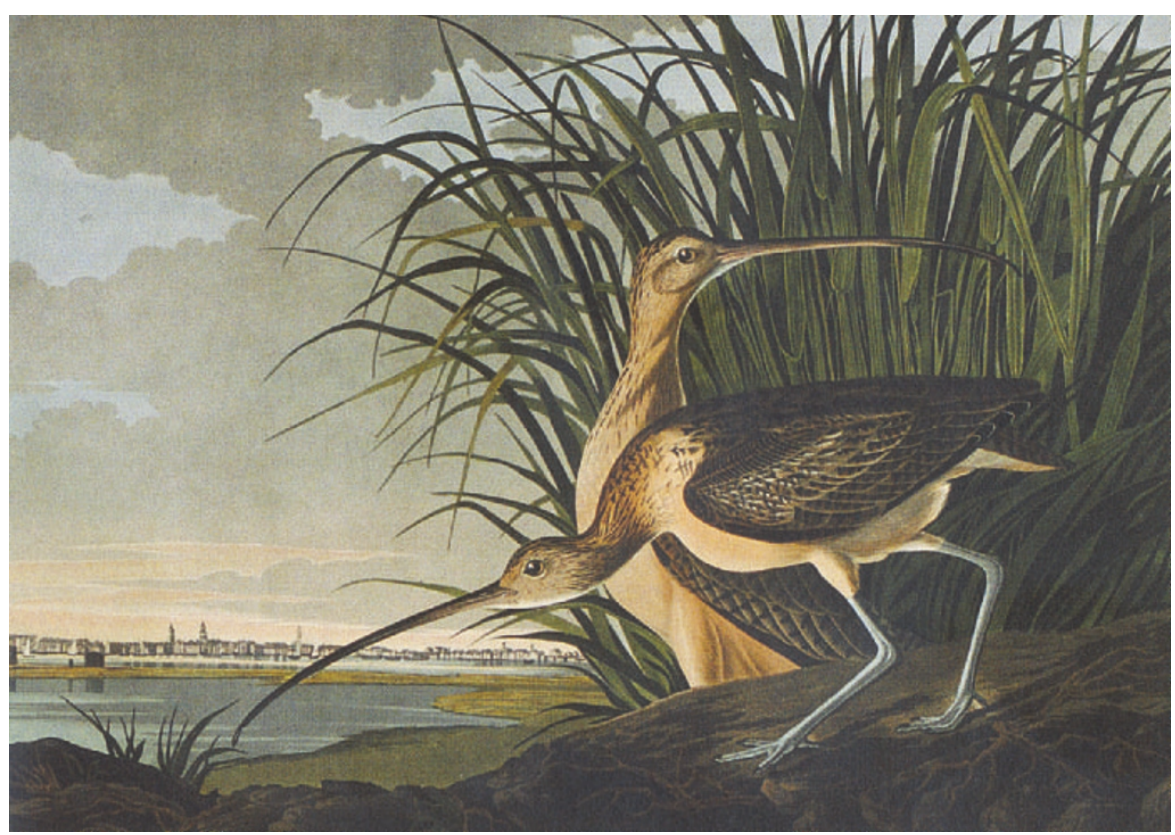

An eye for detail: this image of long-billed curlew is typical of Audubon's bird paintings. 